\title{
A New Load Transfer Model of Skin Friction for Super-long Pile Under Axially Load
}

\author{
Xu XU, Jingjing XU, Wenjuan YAO*, Tingchen FANG
}

\begin{abstract}
In present investigation, a new load transfer model was proposed, in which the softening and strengthening of super-long pile skin friction was considered. The influence of parameters variation on the softening load transfer model was discussed in detail. The load transfer model proposed was verified by engineering results. The nonlinear iterative calculation method of the super-long piles was improved with considering the nonlinear compression model of concrete and the weight of the pile body. Comparing calculation results and the engineering measured data, it demonstrates that the relationship between pile skin friction and the relative displacement and the settlement results are generally in good agreement with the practical engineering results. The skin friction of super-long piles increases with the increase of the depth, while decreases with the increase of the depth near the end of the pile and it has an obvious downward trend. As the load continues to increase, the skin friction near the pile end increases significantly and shows a gradual expansion of the pattern. It completely reflects the softening and strengthening properties of pile skin friction.
\end{abstract}

Keywords: iterative method; load transfer model; softening of skin friction; strengthening model; super-long pile

\section{INTRODUCTION}

The load transfer method proposed by Seed and Reese [1] was a commonly used method to solve the bearing capacity and settlement of single pile and pile groups. The key of load transfer method is to determine the appropriate load transfer model, which can simulate the nonlinear relationship of pile-soil interaction well.

In past few decades, many investigations have been done to investigate the load transfer function. Xin [2] used the simplified trilinear model to carry out the calculation of the softening of pile skin friction, and proposed the calculation method of skin friction at different stages. Yao et al. [3] introduced the trilinear model to take into account the softening of skin friction, and established the analysis model of super-long piles under overload. The trilinear model assumes that the pile-soil interaction is linear, however, the calculation result is quite different from the practical situation. Yin et al. [4] proposed an entire curve softening model. Although the model can simulate the softening performance accurately, the calculation process is too complicated to be popularized. Zhang and $\mathrm{Wu}$ et al. $[5,6]$ proposed a quadratic modified hyperbolic model based on classical hyperbolic models, which can simulate the nonlinearity in the stress-displacement response of soil well. Zhang et al. [7] improved the hyperbolic model to take softening of pile skin friction into consideration. The softening of the skin friction is considered in these models. However, few researchers have been concerned with the strengthening of skin friction, which is not very consistent with the actual mechanical properties of super-long piles.

Basically, due to its large length, the super-long piles have larger bearing capacity than conventional piles. It was found that the pile-soil interface would occur the softening and strengthening of skin friction when piles are loaded [8 -10]. Therefore, it will lead to the deviation of calculation results if the softening and strengthening of skin friction of super-long piles is neglected, and then result in structural instability and material waste.

In view of the above research, this article proposes a new load transfer model for super-long piles considering the softening and strengthening of skin friction. The model can fully simulate the softening and strengthening characteristics of skin friction, which is more consistent with the actual mechanical properties of super-long piles. Besides, it has the advantages of clear physical meaning and a simple selection of the parameters. Considering the nonlinearity of elastic-plastic deformation under high loading level and the weight of super-long piles, an improved iterative algorithm for super-long piles is developed in the present research according to the new load transfer model.

\section{ANALYSIS OF SOFTENING LOAD TRANSFER MODEL 2.1 Softening Load Transfer Model}

Based on the characteristics of skin friction of superlong piles, a load transfer model that considers the softening of skin friction is proposed [11]. It can be expressed by Eq. (1).

$\tau(z)=a \sin [b \cdot \arctan (c \cdot S(z))]$

where $\tau(z)$ is the skin friction; $S(z)$ is the relative displacement; $a$ is the limiting strength of skin friction $\tau_{z u}$, $\tau_{u}$ is the ideal limiting strength of skin friction, which can be calculated by Eqs. (2) and (3) respectively; $b$ is softening parameter, which can be calculated by Eq. (4); $c$ is the relevant parameter of initial shear stiffness $K$ of pilesoil interface, which can be obtained from Eq. (5).

$$
\begin{aligned}
& a=\tau_{z u}=R_{\mathrm{f}} \cdot \tau_{u} \\
& \tau_{u}=K_{h} \tan \delta \sigma_{v}^{\prime}
\end{aligned}
$$

where $R_{\mathrm{f}}$ is the reduction factor of soil; $K_{h}$ is the lateral earth pressure coefficient; $\delta$ is the friction angle of pile-soil interface; $\sigma_{v}^{\prime}$ is the vertical effective stress of soil, which can be calculated by $\sigma_{v}^{\prime}=\gamma z$.

$$
\begin{aligned}
& b=2-\frac{2}{\pi} \arcsin \beta \\
& c=\frac{1}{a b} \tan (K)
\end{aligned}
$$


where $\tau_{r}$ is residual strength of skin friction, assuming that $\beta$ is the ratio of $\tau_{r}$ to $\tau_{z u}$.

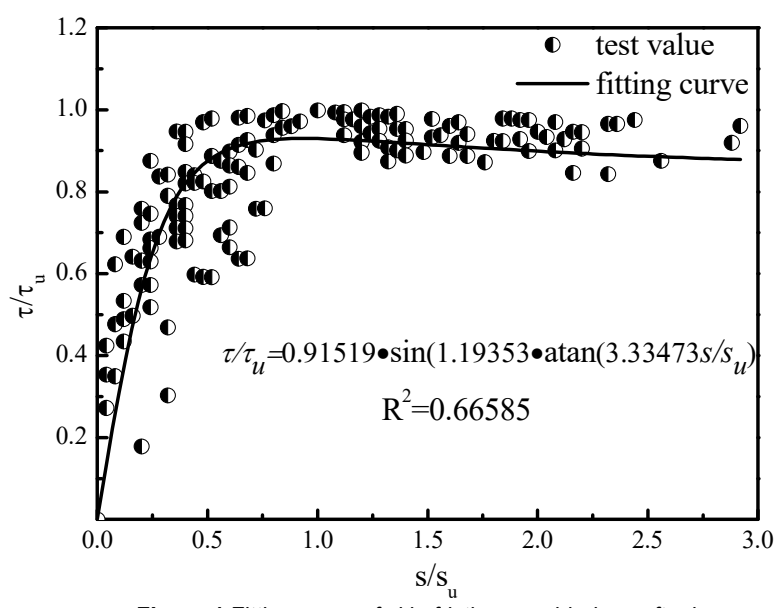

Figure 1 Fitting curve of skin friction considering softening

Zou et al. [12] collected the field-observed and model test data of the piles and normalized the collected data. Taking the ratio of side friction and ultimate friction, $\tau / \tau_{u}$, as the ordinate. At the same time, the ratio of relative displacement and limit displacement, $S / S_{u}$, was taken as the abscissa. It obtained 140 data points after normalization. The softening load transfer model proposed in this research is used to fit the above data, and the fitting curve is shown in Fig. 1. It shows that the fitting correlation coefficient $R^{2}$ of the softening model in this paper is 0.66585 , which is better than that of the exponential model proposed in [12]. $\left(R^{2}=0.61576\right)$. It can well reflect the characteristics of pile side frictional softening, but due to the limited experimental values, the statistical samples are less likely to cause low fitting coefficient.

\subsection{Verification of the Model}

Results of the field test on super-long pile S3 of Wenzhou world trade center [13] are chosen to verify the softening load transfer model proposed. The pile length is $88.35 \mathrm{~m}$ and the diameter of the pile is $1.1 \mathrm{~m}$. The concrete strength of the pile is C40. The bearing stratum is strongly weathered bedrock, and the depth of the pile tip in it is $9.026 \mathrm{~m}$. With the increase of load on the pile top, the softening of pile skin friction changes from 0 to $30.6 \mathrm{~m}$ in depth. Three sections in different soil layers of $0 \sim 30.6 \mathrm{~m}$ are chosen to analysis the relationship of skin friction and the corresponding displacement of pile-soil. The model parameters are computed by Eqs. (2) to (5). The values of parameters used in analysis are shown in Tab. 1.

Table 1 Parameters of soils
\begin{tabular}{|c|c|c|c|c|c|c|c|}
\hline $\begin{array}{c}\text { Soil layer } \\
\text { name }\end{array}$ & $\begin{array}{c}\text { Thickness } \\
/ \mathrm{m}\end{array}$ & $\tau_{u} / \mathrm{kPa}$ & $\beta$ & $S_{u} / \mathrm{mm}$ & $a$ & $b$ & $c$ \\
\hline Silt clay & 9.6 & 12.74 & 0.95 & 19.81 & 12.74 & 1.200 & 0.188 \\
\hline Silt clay & 10 & 18.7 & 0.91 & 18.27 & 18.7 & 1.266 & 0.1598 \\
\hline Clay & 11 & 36.63 & 0.97 & 20.65 & 36.63 & 1.140 & 0.248 \\
\hline
\end{tabular}

Fig. 2 shows the comparison of the calculated results of the softening model in this research and the values given in [13]. It can be seen from that the calculated results are fairly in good agreement with the measured values. The softening load transfer model can be used to simulate the characteristics of the skin friction well. Therefore, the accuracy and applicability of the model proposed in current research are verified.

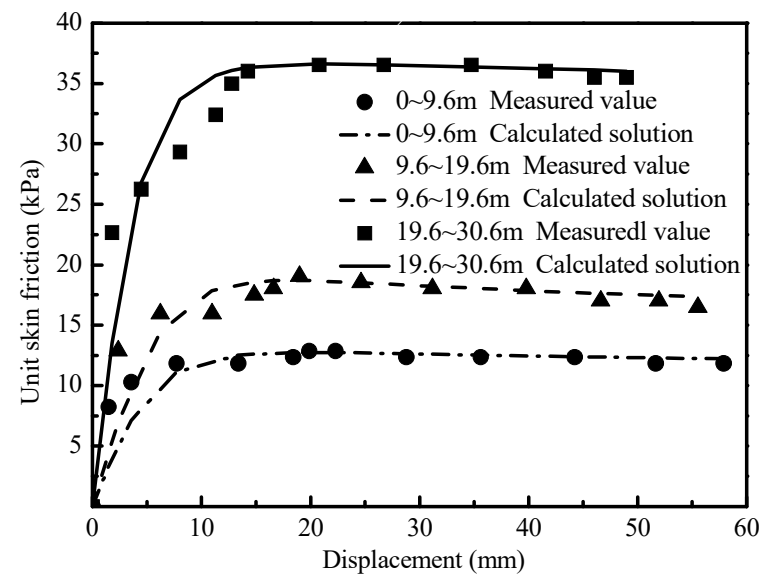

Figure 2 Comparison of measured values and calculated results by the softening model

\subsection{Parametric Analysis}

The super-long pile S1 in [13] is taken to investigate the influence of parameter $a$ on the load transfer model proposed. In this case, $\beta$ is $0.85, S_{u}$ is $10 \mathrm{~mm}$, and $a$ is assumed to be $20 \mathrm{KPa}, 30 \mathrm{KPa}, 40 \mathrm{KPa}$ respectively. The curves of skin friction and pile displacement for various values of $a$ is calculated, as shown in Fig. 3. It can be observed that the value of a determines the peak value and residual stress of the curve. The peak value and residual stress of the curve increase with the increase of $a$.

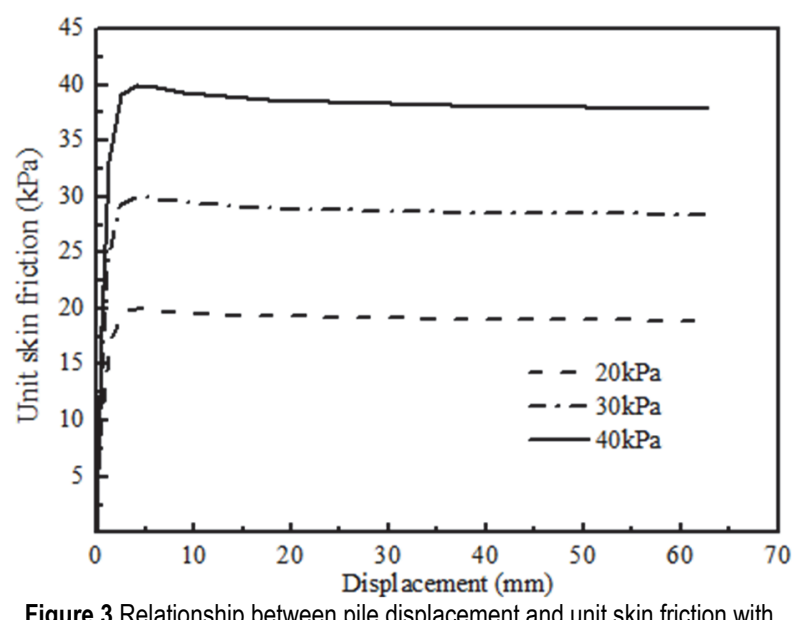

Figure 3 Relationship between pile displacement and unit skin friction with different $a$

The super-long pile S1 could also be an example to analyze the effect of $S_{u}$ on the skin friction of softening model. When $\beta$ is $0.90, \tau_{u}$ is $20 \mathrm{KPa}$, and $S_{u}$ is taken to be $5 \mathrm{~mm}, 10 \mathrm{~mm}, 20 \mathrm{~mm}$ respectively, the curve of skin friction and its corresponding displacement estimated from softening model is shown in Fig. 4. The peak point of the curve moves towards the right side with the increase of $S_{u}$. The value of $S_{u}$ determines the critical relative displacement of pile-soil when the skin friction of pile begins to soften. The softening degree of skin friction decreases with the increase of $S_{u}$, while the residual friction decreases with the increase of $S_{u}$. 


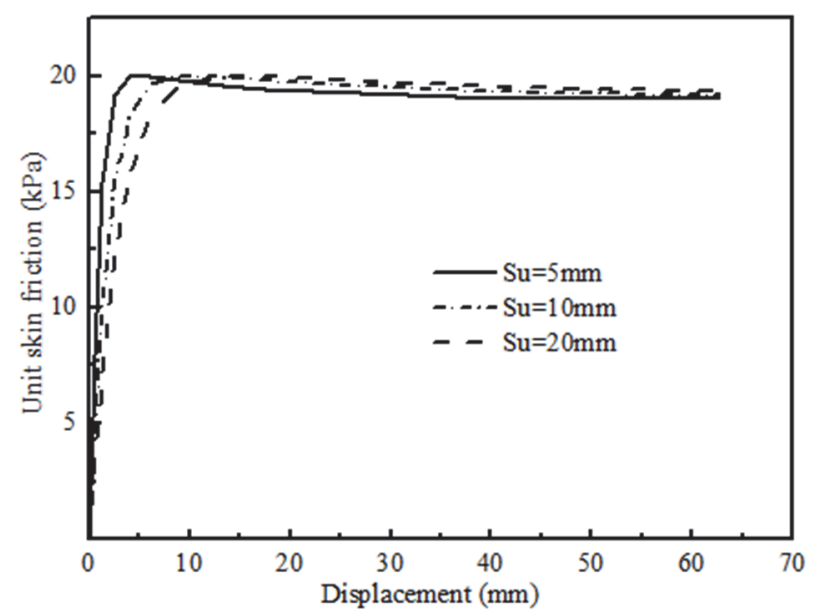

Figure 4 Relationship between pile displacement and unit skin friction with different $S_{u}$

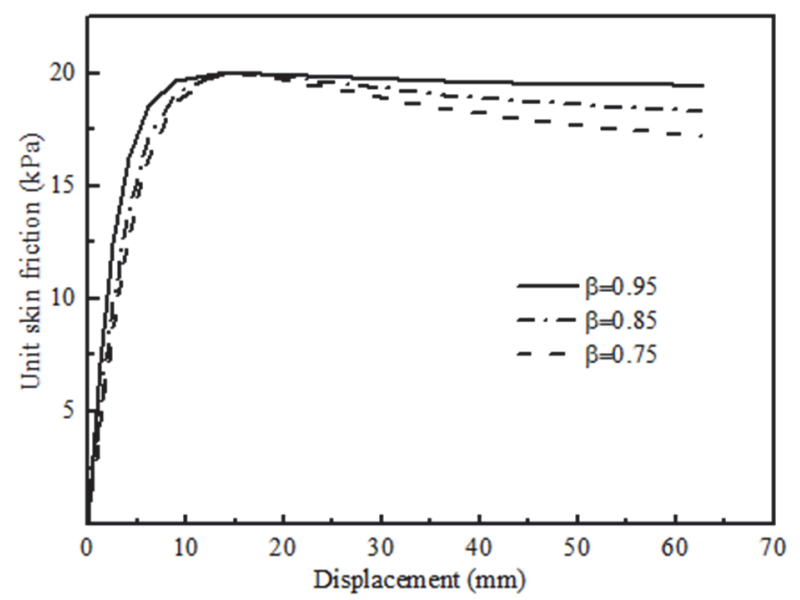

Figure 5 Relationship between pile displacement and unit skin friction with different $\beta$

When analyzing the influence of parameter $\beta$, in this case, selecting $\tau_{u}$ is $20 \mathrm{KPa}, S_{u}$ is $10 \mathrm{~mm}$, and $\beta$ is set as $0.75,0.85$ and 0.95 respectively. The influence of various $\beta$ values on the relationship between unit skin friction and displacement of the softening model is shown in Fig. 5. It can be seen that as the parameter $\beta$ decreases, the residual skin friction of the pile-soil interface becomes lower. And it shows more obvious softening phenomenon. Moreover, the smaller the $\beta$ is, the more the residual skin friction deviates from $\tau_{u}$; the larger the $\beta$, the closer it is to $\tau_{u}$.

\section{ANALYSIS OF STRENGTHENING LOAD TRANSFER MODEL}

\subsection{Strengthening Load Transfer Model}

Wang et al. [14] studied the large diameter and superlong bored test piles in Shanghai center. It was found that the test piles SYZA02 and SYZB01 both had the strengthening of skin friction in the deep soil layers. Zou [15] conducted an experimental research on a pile of $51 \mathrm{~m}$ in length in Beijing CCTV new site and a pile of $56.5 \mathrm{~m}$ in length in Stage A of phase III of International Trade. He found that the skin friction of super-long bored piles in clay layer was softened by processing, while that of sandy soil layer was strengthened. The exertion of super-long pile skin friction had a depth effect as well. Sun [16] analyzed the test data of several typical super-long bored piles, and found that the upper soil layer of lateral resistance was softened and the lower soil layer was strengthened. Therefore, based on the softening load transfer model, a strengthening model is proposed. Introducing parameter " $\lambda$ ", which is the ratio of residual friction to ultimate friction. The skin friction softens when $\lambda<1$, strengthens when $\lambda>1$, and the softening and strengthening of skin friction are not considered when $\lambda=1$. The strengthening model can be expressed as Eq. (6).

$$
\tau(z)= \begin{cases}A_{1} \sin \left[\arctan \left(C_{1} \cdot S z\right)\right] & S \leq S_{u} \\ A_{1}+A_{2} \sin \left[\arctan \left[C_{2} \cdot\left(S z-S_{u}\right)\right]\right. & S>S_{u}\end{cases}
$$

where $S_{u}$ is the ultimate displacement of pile soil; $A_{1}$ is the product of $R_{\mathrm{f}}$ and $\tau_{u} ; A_{2}$ is the difference between the strengthening ultimate skin friction $\tau_{s t}$ and the critical ultimate skin friction $\tau_{z u}$ that begins to strengthen. The initial shear stiffness $K$ of soil is estimated using Eq. (7).

$$
K=\arctan \left(A_{i} C_{i}\right)
$$

The value of $K$ can be obtained by fitting the curve of friction resistance and relative displacement, so the value of $C_{i}$ can also be easily obtained when $i$ equals to 1 or 2 .

\subsection{Verification of the Model}

There is a commercial building in the soft soil area with a height of $150 \mathrm{~m}$ and four basement floors. The test pile $\mathrm{S} 1$ is $1.2 \mathrm{~m}$ in diameter and $72.3 \mathrm{~m}$ in length. The pile tip enters the bearing layer about $3.3 \mathrm{~m}$ [17]. According to the literature, the pile skin friction strengthens obviously in the range of $40 \sim 60 \mathrm{~m}$ buried soil layer. Therefore, the clay and silty clay in this range are selected to confirm the applicability of the strengthening model proposed in this investigation. The specific parameters of the field foundation soil are shown in Tab. 2.

Table 2 Physical and mechanical properties of soils

\begin{tabular}{|c|c|c|c|c|c|c|}
\hline $\begin{array}{c}\text { Soil layer } \\
\text { name }\end{array}$ & $\begin{array}{c}\text { The bottom } \\
\text { layer depth } / \mathrm{m}\end{array}$ & $\begin{array}{c}E \mathrm{~S} / \\
\mathrm{MPa}\end{array}$ & $A_{1}$ & $A_{2}$ & $C_{1}$ & $C_{2}$ \\
\hline $8_{1}$ clay & $52.0 \sim 52.5$ & 4.39 & 54 & 43 & 0.856 & 0.38 \\
\hline $8_{2}$ silty clay & $57.0 \sim 57.7$ & 4.87 & 67.5 & 40.5 & 0.34593 & 0.36814 \\
\hline
\end{tabular}

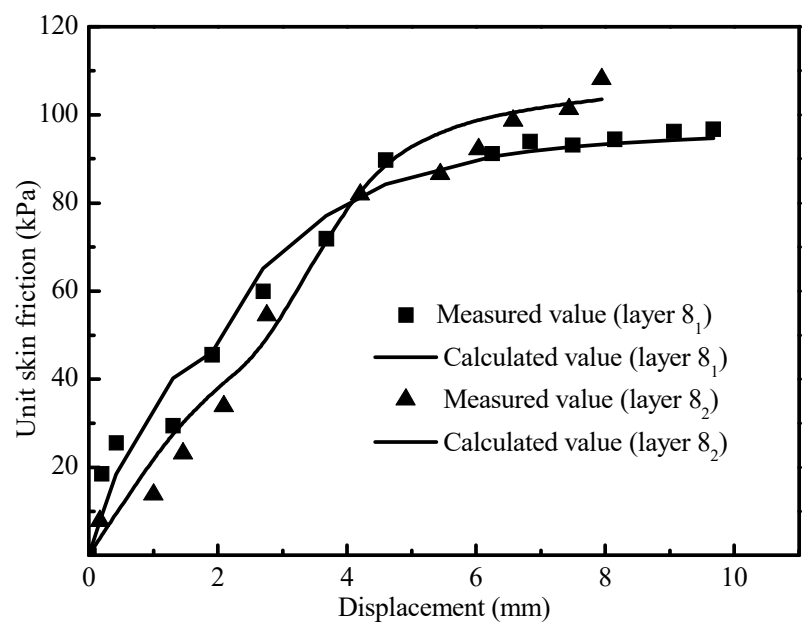

Figure 6 Comparison of measured and calculated results by strengthening model 
Comparison of the measured and calculated relationship between unit skin friction and pile displacement of strengthening model is shown in Fig. 6. It shows that the pile skin friction in the clay and silty clay layers shows obvious "strengthening phenomenon". The strengthening model proposed in this investigation can simulate the relationship between skin friction and relative displacement below the pile body well. The superior consistence between measurement and calculation results demonstrates applicability and rationality of the proposed strengthening model.

\section{AN IMPROVED NONLINEAR ITERATIVE METHOD AND EXAMPLE ANALYSIS}

\subsection{Nonlinearity of Pile Materials}

Due to the larger length-diameter ratio of super-long piles, the concrete of pile body will show plastic deformation under high-level loads. Therefore, there is a need to consider the non-linearity of pile material in the calculation. At present, the commonly used concrete elastic-plastic models include the Rusch model, the Hognested model, and Guo model [10]. Although the curves of the three calculation models are different from each other to some extent, they are consistent when $\varepsilon \leq \varepsilon_{0}$. Under the working load, the bearing capacity of concrete of a super-long pile normally does not exceed its designed carrying capacity. The situation of $\varepsilon \leq \varepsilon_{0}$ is taken into consideration only. $\sigma_{c}$ can be expressed as Eq. (8).

$$
\sigma_{c}=\sigma_{0}\left[\frac{2 \varepsilon}{\varepsilon_{0}}-\left(\frac{\varepsilon}{\varepsilon_{0}}\right)^{2}\right]
$$

where $\sigma_{c}$ is concrete stress; $\sigma_{0}$ is the peak stress, it is equal to the axial compressive strength $f_{c}$ under Uniform compression; $\varepsilon_{0}$ is the limiting strain value under uniform compression, and choose a value of 0.002 for $\varepsilon_{0}$.

Under the working load, the steel bar and concrete in the reinforced concrete piles deform harmoniously. The reinforcement ratio of longitudinal bar is $\rho_{s v}$. The elastic modulus of steel bar is $E_{s v}$, assuming $E s$ as $2.0 \times 10^{5} \mathrm{~N} / \mathrm{mm}^{2}$. Then the stress at any section of the pile can be expressed by Eq. (9):

$$
\sigma=\sigma_{c}+\rho_{s v} E_{s v} \varepsilon
$$

Substituting Eq. (8) into Eq. (9), then take the derivative of the expression with respect to $\varepsilon$. Before the failure of pile concrete, the elastic modulus $E_{p}$ of pile can be expressed by the following equation:

$$
E_{p}=\frac{\mathrm{d} \sigma}{\mathrm{d} \varepsilon}=\frac{2 \sigma_{0}}{\varepsilon_{0}}\left(1-\frac{\varepsilon}{\varepsilon_{0}}\right)+\rho_{s v} E_{s v}
$$

\subsection{Improved Iterative Algorithm}

For super-long piles, when the load of pile top is relatively low, the skin friction at the lower part of critical pile length is not exerted. And the traditional calculation method of solving pile settlement based on the assumption that a small displacement occurs at pile end has an error. Therefore, based on the problems above, the paper assumes a small displacement at the top of super-long pile to solve it. Considering the weight of super-long piles, and the displacement at the pile top is continuously adjusted by dichotomy, so that the calculated results and measured values are within the allowable accuracy range. The detailed analysis is as following procedure:

(1) Assume that a single pile is divided into $n$ segments along with the pile.

(2) Assume a small pile top settlement, $S_{t 1}$, which conducted by pile top load, $P_{t 1}$.

(3) Ignore the influence of skin friction on segment 1 , the deformation of segment 1 can be calculated by Eq. (11).

$$
S_{c 1}=\frac{P_{t 1} \Delta L_{1}}{A_{p} E_{0}}
$$

where $A_{p}$ and $E_{0}$ are the cross-sectional areas and initial elastic modulus of super-long piles respectively; $\Delta L_{1}$ is the length of segment 1 . (12).

(4) Calculate the strain value $\varepsilon_{1}$ of segment 1 by Eq.

$$
\varepsilon_{1}=S_{c 1} / \Delta L_{1}=\frac{P_{t 1}}{A_{p} E_{0}}
$$

$E_{p 1}$, which is modified elastic modulus, is obtained by introducing $\varepsilon_{1}$ into Eq. (10), then $S_{c 1}^{\prime}$ is obtained by introducing $E_{p 1}$ into Eq. (10). There are some details need to be noted: In order to reduce the number of iterations and make the results converge faster, the initial assumed pile strain value should not be too large. The strain increment of pile strain and initial pile strain,

$\left|S_{c 1}^{\prime}-S_{c 1}\right|$, was calculated based on convergence criterion of Euclidean norm. When it exceeds $10^{-6}$, let $S_{c 1}$ $=S_{c 1}^{\prime}$, repeat the iterative steps until the strain increment is less than the control error. Then, $E_{p 1}$ and $S_{c 1}^{\prime}$ will be obtain.

(5) Calculate the movement, $S_{1}$, at the middle height of pile segment 1 .

$$
S_{1}=\mathrm{S}_{t 1}-\frac{1}{2} S_{c 1}^{\prime}
$$

(6) By substituting $S_{1}$ into Eq. (1) (for softening) or Eq. (6) (for strengthening), the shear stress $\tau_{1}$ of pile segment 1 is obtained. And the total skin friction of pile segment 1 is calculated by Eq. (14).

$$
T_{1}=2 \pi r_{0} \Delta L_{1} \tau_{1}
$$

(7) Calculate the mobilized pile baseload, $P_{b 1}$.

$$
P_{b 1}=P_{t 1}+\gamma_{c} A_{p} \Delta L_{1}-T_{1}
$$

where $\gamma_{c}$ is the unit concrete weight of super-long pile body.

(7) Calculate the average load of segment 1.

$$
P_{1}=\frac{1}{2}\left(P_{t 1}+P_{b 1}\right)
$$


(8) Modify the deformation of pile. Substitute $P_{1}$ into Eq. (11), and compare $S^{\prime \prime}{ }_{c 1}$ have got with $S_{c 1}^{\prime}$. Repeat above steps until $\left|S^{\prime \prime}{ }_{c 1}-S_{c 1}^{\prime}\right| \leq 10^{-5}$.

(9) Calculate the deformation at the base of segment 1.

$S_{b 1}=S_{t 1}-S_{c 1}^{\prime \prime}$

(10) According to the principle of displacement coordination and force balance, the pile top load and displacement of segment 2 are calculated by $P_{t 2}=P_{b 1}$ and $S_{t 2}=S_{b 1}$ respectively.

(11) Repeat the above steps, the pile top load $P_{t i}$ and the pile top displacement $P_{t i}$ of segment $i$ can be obtained. When $P_{t i}$ or $S_{t i}$ is less than zero, the calculation stops.

(12) Calculate the total load $T$ of pile side.

$T=T_{1}+T_{2}+, \ldots,+T_{i}$

or

$T=T_{1}+T_{2}+, \ldots,+P_{b}$

where $P_{b}$ is pile base load. If the difference between the calculated $T$ and the assumed $P_{t 1}$ of pile top is within the allowable range, then $S_{t 1}$ is the corresponding displacement of pile top when the pile top load is $P_{t 1}$.

(13) Suppose the pile top displacement of segment 1 is $S_{t 1}^{\prime}$ (if $T$ is greater than the assumed pile top load $P_{t 1}$, then the assumed value of $S_{t 1}^{\prime}$ should be less than $S_{t 1}$. On the contrary, assuming that $S_{t 1}^{\prime}$ is large than $S_{t 1}$ ), then the average displacement of pile top can be obtained by Eq. (20).

$S_{t 1}^{a}=\frac{1}{2}\left(S_{t 1}+S_{t 1}^{\prime}\right)$

Repeat step (3) to (13), then total load $T^{\prime}$ of pile side is obtained.

(14) If $\left|P_{t 1}-T^{\prime}\right|$ is less than the limit value of $0.1 \mathrm{kN}$, $S^{a}{ }_{t 1}$ is the settlement at top of pile when the load is $P_{t 1}$. If $\left(P_{t 1}-T^{\prime}\right)\left(P_{t 1}-T\right)$ is less than zero, then suppose $S_{t 1}^{\prime}$ equals to $S^{a}{ }_{t 1}$ and repeat above steps. If $\left(P_{t 1}-T^{\prime}\right)\left(P_{t 1}-T\right)$ is more than zero, then suppose $S_{t 1}$ equals to $S^{a}{ }_{t 1}$ and repeat above steps until the value of $\left|P_{t 1}-T^{\prime}\right|$ is within the assumed tolerance.

(15) Assume the different values of $S_{t 1}$ and $P_{t 1}$ and repeat the above steps until the displacement values of super-long piles head under different load are obtained.

\subsection{Example 1}

The engineering example in which only softening of skin friction occurred is selected for analysis to further verify the softening model of the skin friction [18]. Engineering in Wenzhou has 28-32 floors above ground and uses bored cast-in-place piles in the foundation. The diameter of test pile S2 is $1000 \mathrm{~mm}$ and the depth of the piles is $95.14 \mathrm{~m}$. The bearing stratum is weathered tuff. There are 11 groups of steel bar stress gauges installed on the pile S2. And the slow maintenance load method is adopted for static load test. The specific calculation parameters of field soil are shown in Tab. 3 .
Table 3 Physical and mechanical properties of soils

\begin{tabular}{|c|c|c|c|c|c|}
\hline Number & $\begin{array}{c}\text { Soil layer } \\
\text { name }\end{array}$ & $\begin{array}{c}\text { Depth } / \\
\mathrm{m}\end{array}$ & Thickness/m & $\begin{array}{c}Y / \\
\mathrm{kN} \cdot \mathrm{m}^{-3}\end{array}$ & $\tau_{u} / \mathrm{kPa}$ \\
\hline 1 & Filling & 1.7 & 1.7 & 17.3 & 5 \\
\hline 2 & Clay & 2.3 & 0.6 & 18.2 & 10 \\
\hline 3 & Silt & 25.6 & 23.3 & 16.3 & 38.9 \\
\hline 4 & Muddy clay & 42.8 & 17.2 & 17.4 & 42.3 \\
\hline 5 & Silty clay & 55.1 & 12.3 & 20.3 & 125.3 \\
\hline 6 & The clay & 65.1 & 10 & 19.3 & 63.7 \\
\hline 7 & Muddy clay & 76.6 & 11.5 & 18.5 & 35.7 \\
\hline 8 & Clay & 86.4 & 9.8 & 18.9 & 116.8 \\
\hline 9 & Clay & 92.4 & 6 & 19 & 120 \\
\hline 10 & Silty clay & 94.5 & 2.1 & 19.7 & 160 \\
\hline 11 & $\begin{array}{c}\text { Fully } \\
\text { weathered } \\
\text { tuff }\end{array}$ & 96.8 & 2.3 & 18.9 & 65 \\
\hline \multicolumn{7}{|c|}{} & \multicolumn{3}{|l}{} \\
\hline
\end{tabular}

Comparisons among calculated load-settlement behavior obtained from proposed method, experimental values and calculated values given by Wang [10] are shown in Fig. 7. Comparisons of pile axial force in different methods are shown in Fig. 8. Although the elastic-plastic deformation of pile concrete is considered in the calculation of Wang, the softening of shear stress is not considered in it. The calculation method presented in this investigation considers not only the elastic-plastic deformation of pile body, but also the softening of skin friction of super-long piles.

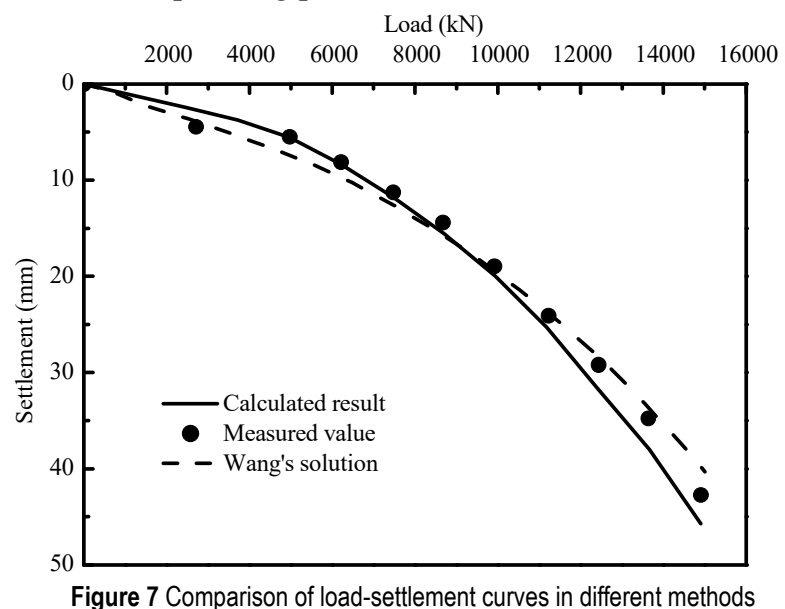

$\mathrm{P}(\mathrm{kN})$

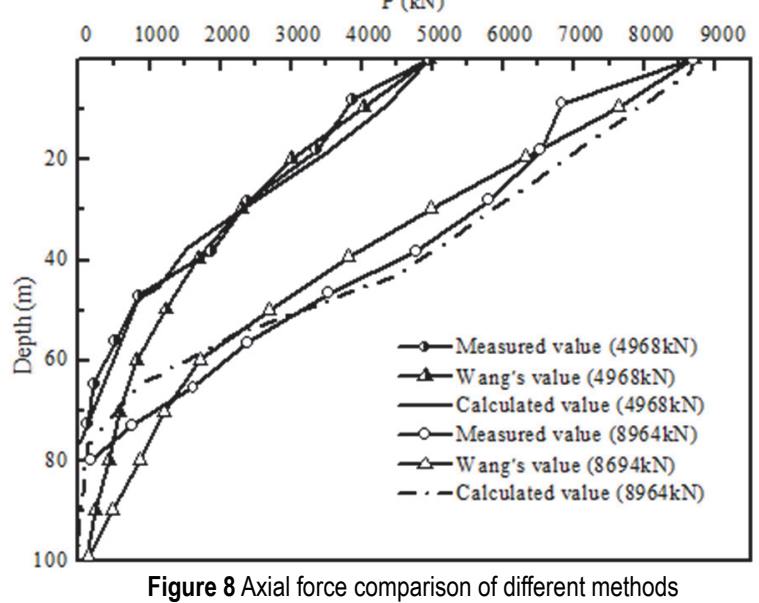

It can be seen from Figs. 7 and 8 that the improved iterative algorithm proposed in this paper, which takes into account of both the softening of skin friction and the elastic-plasticity of pile body materials, can better simulate the relationship between load-settlement response at the 
pile head. The calculated solution presented is in better agreement with the test results, the method proposed in the paper is more in line with the actual mechanical behavior of super-long piles.

\subsection{Example 2}

The mechanical properties of super-long pile that upper soil softening and lower strengthening are analyzed by an engineering example in soft soil area. The diameter is $1.0 \mathrm{~m}$ of pile SYZA02 of Shanghai center, and the pile is $88 \mathrm{~m}$ in length [14]. There is $25 \mathrm{~m}$ steel casing is adopted to separate soil from pile body, at the same time, the weight of steel casing and pile body are considered in calculation. The specific parameters of the field soil are shown in Tab. 4.
Figs. 9 and 10 show the variation curves of skin friction along the pile by different methods when the load applied on the pile top is $12000 \mathrm{KN}$ and $25000 \mathrm{KN}$, respectively. There is a sleeve of $25 \mathrm{~m}$ in length on the pile top, which isolates the interaction of pile and soil. Therefore, the skin friction is equal to 0 when the depth is less than $25 \mathrm{~m}$.

It can be seen that when the load on the top of the pile is $12000 \mathrm{KN}$, the skin friction of the upper pile increases with the increase of the depth, while the skin friction decreases with the increase of the depth at the lower part of the pile. The calculated results in this investigation are consistent with the field observations. There is an obvious degradation of the skin friction at the lower part of the pile, while the decreasing tendency cannot be performed using simulation.

Table 4 Parameters of soil

\begin{tabular}{|c|c|c|c|c|c|c|c|c|}
\hline Soil layer name & Thickness / m & $Y / \mathrm{kN} \cdot \mathrm{m}^{-3}$ & $c / \mathrm{KPa}$ & $\varphi /{ }^{\circ}$ & $E \mathrm{~s} / \mathrm{MPa}$ & $v$ & $\lambda$ & $R \mathrm{f}$ \\
\hline Clayey silt & 1 & 18.4 & 20 & 18 & 15 & \multirow{11}{*}{0.3} & - & - \\
\hline Muddy silty clay & 4.9 & 17.7 & 10 & 22.5 & 12 & & - & - \\
\hline Muddy clay & 8.1 & 16.7 & 14 & 11.5 & 7.5 & & - & - \\
\hline Clay & 4 & 17.6 & 16 & 14 & 15 & & - & - \\
\hline Silty clay & 4.8 & 18.4 & 15 & 22 & 15 & & - & - \\
\hline Silty clay & 3.6 & 19.8 & 45 & 23.7 & 22.5 & & $<1$ & 0.30 \\
\hline Silty Sand & 9.7 & 18.7 & 3 & 32.5 & 11.5 & & $<1$ & 0.45 \\
\hline Silty Sand & 26 & 19.2 & 0 & 35 & 48.0 & & $<1$ & 0.40 \\
\hline Silty Sand & 5 & 19.1 & 2 & 37 & 45.0 & & $>1$ & 0.90 \\
\hline Sandy Silt & 7 & 19.1 & 5 & 36 & 45.0 & & $>1$ & 0.90 \\
\hline Silty Sand & 20.4 & 20.2 & 0 & 39 & 47.6 & & $>1$ & 0.90 \\
\hline
\end{tabular}

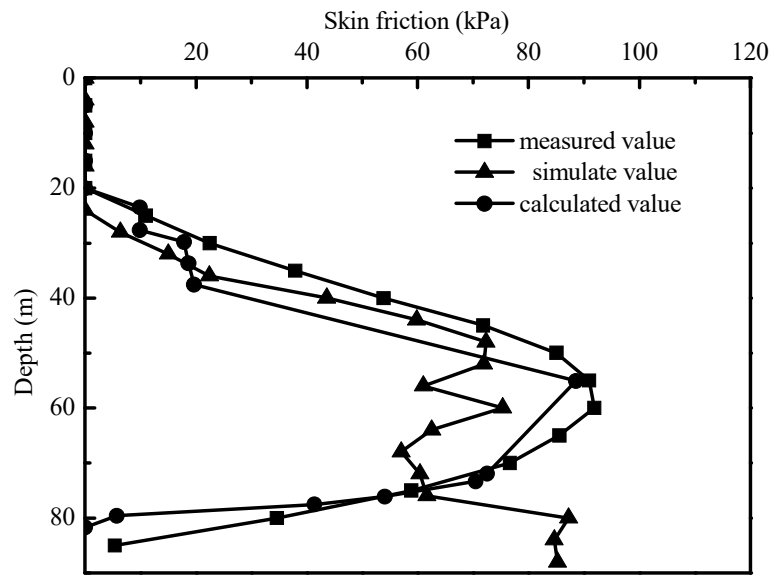

Figure 9 Comparison of skin friction when vertical load is $12000 \mathrm{kN}$

Fig. 10 shows the comparison of the measured value, simulated value of reference [19] and calculated value in this paper. In this paper, the calculation curve of considering the upper softening and the lower reinforcement of the pile side friction are very consistent with the whole curve of the measured values. However, since the simulated value of the reference [19] only considered the softening of the lateral friction resistance at upper part of the pile, the strengthening of the lateral friction resistance at the lower part of the pile was not considered. Therefore, there was a serious discrepancy between the simulated value obtained by the predecessors and the measured value in the lower part of the pile. This exactly shows the rationality of model considering the strengthening of pile lateral friction in this paper. When the load of pile top increases to $25000 \mathrm{kN}$, the skin friction increases continuously along with the pile and increases obviously near the pile tip. The calculated and simulation results are consistent with this trend. However, compared with simulation results only considering the degradation of skin friction, the present calculated results considering the softening and strengthening of skin friction are closer to the test values.

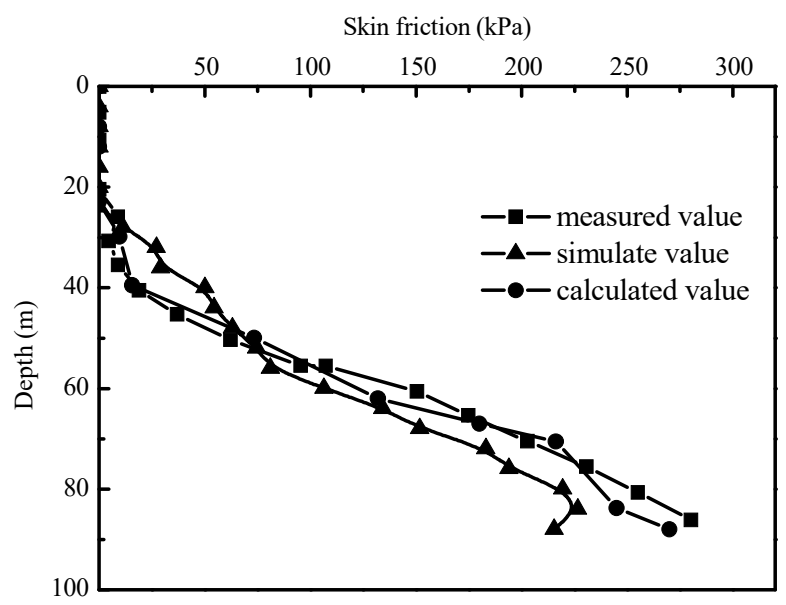

Figure 10 Comparison of skin friction when vertical load is $25000 \mathrm{kN}$

Fig. 11 shows the skin friction of super-long piles at the different burial depths with increasing load on the top of piles. The field-observed results show that the pile skin friction softens and strengthens respectively when it is at the buried depth of $50 \mathrm{~m}$ and $82 \mathrm{~m}$. As a result, the two sections are taken as the research objects in this investigation.

By comparing the experimental values with the calculated values given by present method at the depth of $50 \mathrm{~m}$ and $82 \mathrm{~m}$, it can be seen that the softening model and 
strengthening model presented in this investigation can better simulate the variation characteristics of skin friction with pile top load, and the skin friction along pile obtained using the proposed method is generally consistent with the measured values. Meanwhile, the applicability and accuracy of the softening model and the strengthening model of pile skin friction proposed are further confirmed.

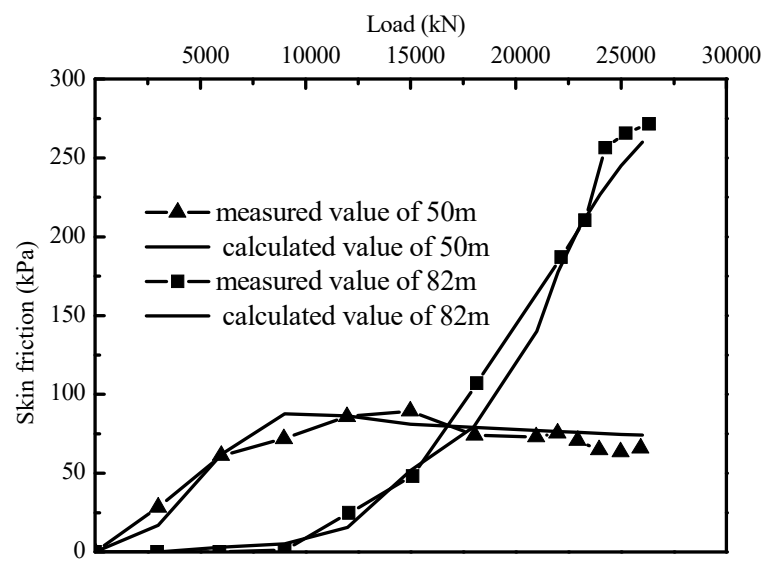

Figure 11 Comparison of skin friction under different load

The comparison of measured value, results only considering the softening of skin friction given by Xu et al. [19] and the present computed values of considering softening and strengthening are shown in Fig. 12. When the pile top load is less than $20000 \mathrm{kN}$, the response of present approach is between the rest. Moreover, it is closer to the measured values. When the pile top load exceeds 20000 $\mathrm{kN}$, the calculated results are slightly less than the measured values. However, they are closer to the measured values than the finite element method only considering softening.

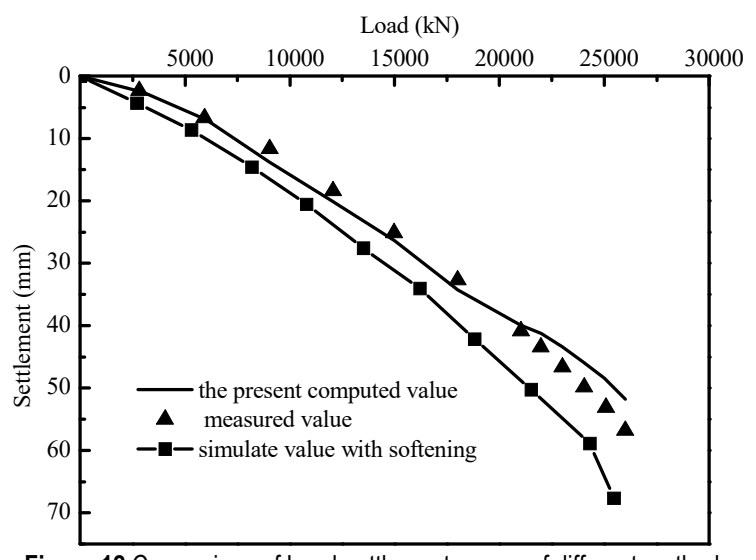

Figure 12 Comparison of Load-settlement curves of different methods

In view of the similar engineering conditions, the calculation method of considering softening of the upper super-long pile and strengthening of the lower part is more suitable for the variation of the skin friction of the superlong pile. It can also more accurately estimate the mechanical behavior of the super-long piles.

\section{CONCLUSIONS}

1) It is a new load transfer model proposed in this paper to analyze the softening and strengthening characteristics of skin friction of super-long piles. The softening model and strengthening model of super-long piles are verified by the field-observed data. The results illustrate that the relationship between skin friction and relative displacement calculated by proposed method in present research shows a well consistency with the practical engineering, which proves the rationality and applicability of the softening model and the strengthening model proposed.

2) The nonlinear iterative calculation method of superlong pile under vertical load is improved considering the elastoplastic deformation of concrete and the softening and strengthening characteristics of the skin friction. Compared with the engineering examples show that the calculation method in this research can accurately reflect the actual mechanical behaviors of super-long piles. The skin friction of axially loaded super-long pile increases with the increase of depth. And near the end of pile, the skin friction decreases with the increase of depth which has an obvious descending section. As the load on pile top continues to increase, the skin friction near the pile end increases significantly, showing a gradual expansion pattern. The results are definitely consistent with the softening and strengthening characteristics of pile skin friction.

\section{Acknowledgements}

This work was gratefully supported by the National Key R\&D Program Project (No. 2018YFF0300301) and the National Natural Science Foundation of China (No. 11272200, No. 11572186).

\section{REFERENCES}

[1] Seed, H. B. \& Reese, L. C. (1957). The Action of Soft Clay Along Friction Piles. Transactions of the American Society of Civil Engineers, ASCE, 122(1), 731-754. https://doi.org/10.1061/TACEAT.0007501

[2] Xin, G. F. (2003). Studies on Bearing and Deformation Mechanism and Shaft Resistance Degradation of Superlong Piles Under Vertical Loading. PhD Thesis, Zhejiang University, Hangzhou, China.

[3] Yao, W. J., Liu, Y. M., \& Chen, J. (2012). Characteristics of Negative Skin Friction for Super-Long Piles Under Surcharge Loading. International Journal of Geomechanics, ASCE, 12(2), 90-97.

https://doi.org/10.1061/(ASCE)GM.1943-5622.0000167

[4] Yin, C. J., Ma, S. C., \& Wang, X. H. (2008). Analysis of Load-Settlement Curve of Single Pile when Soil around Pile is Nonlinear Softening. Natural Science Journal of Xiangtan University, 30(2), 72-76.

[5] Zhang, Q. Q. (2012). Experimental and Theoretical Study on Mechanical Behavior and Settlement Characteristics of Pile Foundation in Soft Soil Foundation. PhD Thesis, Zhejiang University, Hangzhou, China.

[6] Wu, Y. D., Liu, G. C., Liu, J., Luo, R. P., \& Chen, R. (2017). Load Transfer Law of Single Pile Based on Pile-Soil Softening Model. Science Technology and Engineering, 17(14), 262-267.

[7] Zhang, J., Zhang, S. M., Zhang, Q. Q., Liu, S. W., \& Feng, R. F. (2018). Analysis of the Response of An Axially Loaded Pile Considering Softening Behavior of Pile-Soil System. Soil Mechanics and Foundation Engineering, 55(1), 25-32. https://doi.org/10.1007/s11204-018-9497-1

[8] Zhong, W. H. (2005). Study on Load Transfer Characteristics and Interaction Theory and Application of 
Deep and Long Piles. PhD Thesis, Southeast University, Nanjing, China.

[9] Zhang, Z. M. \& Xin, G. F. (2003). Analysis of the Endurance of Super-Long Piles in Soft Soil Foundation. Geotechnical Investigation \& Surveying, 31(3), 10-13.

[10] Wang, Z. J. (2013). Study on Settlement Calculation and Time Effect of Pile Foundation Considering Pile-Soil Relative Displacement. PhD Thesis, Zhejiang University, Hangzhou, China.

[11] Pacejka, H. B. \& Bakker, E. (1992). The Magic Formula Tyre Model. Vehicle system dynamics, 21, 1-18. https://doi.org/10.1080/00423119208969994

[12] Zou, J., Zhang, Z. M., Liu, J. W., \& He, J. Y. (2011). A Load Transfer Function Considering Strain Softening of PileSide Soil. Chinese Journal of Geotechnical Engineering, 32(7), 1109-1113.

[13] Zhang, Z. M., He, J. Y., Zhang, Q. Q., \& Zeng, L. C. (2010). Measured Settlements of Super-Long Piles and Pile Groups for A Building of $323 \mathrm{~m}$ in Height in Wenzhou. Chinese Journal of Geotechnical Engineering, 32(3), 330-337.

[14] Wang, W. D., Li, Y. H., \& Wu, J. B. (2011). Field Loading Tests on Large-Diameter and Super-Long Bored Piles of Shanghai Center Tower. Chinese Journal of Geotechnical Engineering, 33(12), 1817-1826.

[15] Zou, D. F. (2013). Behaviors of Bearing Capacity of UltraLong Bored Piles in Beijing. Chinese Journal of Geotechnical Engineering, 35(S1), 388-392.

[16] Sun, H. W. (2011). Compare Analysis on Loading Test Data of Ultra-Long Bored Piles in Beijing, Tianjin and Shanghai. Building Structure, 41(9), 143-146.

[17] Shen, X. M. (2006). Test Research on Vertical Bearing Capacity of Super-long Large-Diameter Base-Grouting Bored Piles in Soft Soil. Building Structure, 36(4), 34$36+67$.

[18] Zhu, X. R., Fang, P. F., \& Huang, H. M. (2003). Research on Super-Long Pile in Soft Clay. Chinese Journal of Geotechnical Engineering, 25(1), 76-79.

[19] Xu, X., Wang, X. M., Cai, C. Y., \& Yao, W. J. (2018) Improved Calculation Method of Super-Long Pile in Deep Soft Soil Area. International Journal of Geomechanics, ASCE, 18(10), 1-11.

https://doi.org/10.1061/(ASCE)GM.1943-5622.0001223

\section{Contact information:}

Xu XU, Professor

School of Mechanics and Engineering Science, Shanghai University,

No. 99, Shangda Road, Shanghai 200444, P. R. China

E-mail: xuxuofshu@163.com

Jingjing XU, doctoral student

School of Mechanics and Engineering Science, Shanghai University,

No. 99, Shangda Road, Shanghai 200444, P. R. China

E-mail: JINGX@i.shu.edu.cn

Wenjuan YAO, Professor

(Corresponding Author)

School of Mechanics and Engineering Science,

Institute of Applied Mathematics and Mechanics, Shanghai University,

No. 99, Shangda Road, Shanghai 200444, P. R. China

E-mail: wjyao@shu.edu.cn

Tingchen FANG, senior engineer

Shanghai Construction Group Co., Ltd.

No. 666, East Daming Road, Hongkou District, Shanghai 200082, P. R. China,

E-mail: fangtc@scgtc.com.cn 